\title{
Salvage high intensity focused ultrasound versus salvage radical prostatectomy for radiation-recurrent prostate cancer: a comparative study of oncological, functional and toxicity outcomes.
}

Devos Brecht ${ }^{1}$, Al Hajj Obeid Walid ${ }^{2,3}$, Andrianne Colin ${ }^{3}$, Diamand Romain ${ }^{3}$, Peltier Alexandre ${ }^{3}$, Everaerts Wouter ${ }^{4}$, Van Poppel Hein ${ }^{4}$, Van Velthoven Roland ${ }^{3}$, Joniau Steven, ${ }^{4, *}$

${ }^{1}$ KU Leuven, Faculty of Medicine, Leuven, Belgium.

${ }^{2}$ Saint George Hospital University Medical Center, Department of Urology, Beirut, Lebanon.

${ }^{3}$ Jules Bordet Institute, Department of Urology, Brussels, Belgium.

${ }^{4}$ University Hospitals Leuven, Department of Urology, Leuven, Belgium.

* Corresponding author:

Prof. Dr. Steven Joniau, MD, PhD

Department of Urology

University Hospitals Leuven

Herestraat 49

3000 Leuven

Belgium

Steven.Joniau@uzleuven.be

Tel. secr. +3216346930

ORCID https://orcid.org/0000-0003-3195-9890 


\begin{abstract}
Purpose: To compare oncological, functional and toxicity outcomes of patients with radiationrecurrent prostate cancer (PCa) after external beam radiation therapy (EBRT) or brachytherapy (BT) treated with salvage high intensity focused ultrasound (S-HIFU) or salvage radical prostatectomy (S$\mathrm{RP})$.

Methods: This retrospective study compared 52 patients with radiation-recurrent PCa after EBRT or BT treated with S-HIFU $(n=27)$ or S-RP $(n=25)$ between 1998 and 2016. We estimated overall survival (OS), cancer-specific survival (CSS) and metastasis-free survival (MFS) at 5 years. Incontinence after local salvage therapy (LST) was scored according to the number of pads used per day. Complications were graded according to the Clavien-Dindo classification.

Results: Both groups were similar for pre-LST tumor features, however no S-HIFU patients received BT and S-RP patients were younger and healthier. Median follow-up was 45 months for S-HIFU and 43 months for S-RP. No significant differences were found in estimated 5-year OS (80.9\% vs. 61.9\%, $\mathrm{p}=0.24)$, 5 -year CSS $(84.0 \%$ vs. $74.0 \%, \mathrm{p}=0.36)$ and 5 -year MFS $(60.3 \%$ vs. $55.2 \%, \mathrm{p}=0.55)$ for S-HIFU vs. S-RP, respectively. We observed a significant difference in pad-dependent status at 12 months $(22.2 \%$ vs. $56.0 \%, \mathrm{p}=0.01)$ and in the number of Clavien $\geq$ III complications $[9(7 / 27$ patients) vs. 16 (12/25 patients), $p=0.027$ ] in favor of S-HIFU vs. S-RP, respectively.

Conclusion: S-HIFU and S-RP could both be considered valuable LST options for patients with radiation-recurrent nonmetastatic PCa with sufficient life expectancy. S-RP is associated with more pad-dependent patients at 12 months.
\end{abstract}

Keywords: high intensity focused ultrasound; radical prostatectomy; PSA; radiation-recurrent prostate cancer; salvage therapy; radiotherapy 


\section{Introduction}

There is currently no standard of care for locally recurrent prostate cancer (PCa) after failed radiotherapy (RT) [1]. Selected patients with histologically proven local recurrence without evidence of metastatic disease are eligible for local salvage treatment (LST) with curative intent. Other options are expectant management or androgen deprivation therapy (ADT), even though ADT has no curative intent and can have significant side effects [2,3].

It is known that $20-30 \%$ of all radiation-recurrent PCa are classified as local recurrences [4]. Four different LST options for this specific disease state are currently offered: salvage radical prostatectomy (S-RP), salvage brachytherapy, salvage cryoablation, and salvage high intensity focused ultrasound (SHIFU) [1, 5]. Irreversible electroporation is now being investigated as a promising fifth LST using nonthermal high-voltage electrical pulses [6]. Recent findings show that minimally invasive therapies offer similar overall survival (OS) and biochemical disease-free survival (bDFS) rates compared to S$\mathrm{RP}$, while revealing a trend towards lower associated morbidity $[1,7]$.

In this study, we aimed to retrospectively compare the oncological, functional and toxicity outcomes of S-HIFU vs. S-RP in patients with radiation-recurrent PCa following external beam radiation therapy (EBRT) or brachytherapy (BT). Primary endpoints were 5-year estimated OS, cancer-specific survival (CSS) and metastasis-free survival (MFS). Secondary endpoints were incontinence rates scored by the number of pads used per day and perioperative complications according to the Clavien-Dindo classification of surgical complications.

\section{Material and methods}

We retrospectively analyzed the medical records of patients who underwent whole-gland S-HIFU or S$\mathrm{RP}$ at two independent Belgian centers (University Hospitals Leuven and Institute Jules Bordet Brussels) between 1998 and 2016. 26/27 (96.3\%) of S-HIFU and 19/25 (76.0\%) of S-RP treatments were performed between 2006 and 2016 with approximately 2-3 cases per year of each modality.

Inclusion criteria were a biochemical recurrence (BCR) according to the Phoenix definition (PSA nadir $+2 \mathrm{ng} / \mathrm{mL}$ ) and a positive biopsy following EBRT or BT, a negative metastatic evaluation using computed tomography (CT) of the chest and abdomen and bone scan. Choline PET-CT or magnetic resonance imaging (MRI) were considered valid alternatives for the CT chest/abdomen. Patients were excluded if they did not receive primary EBRT or BT, had metastases, had a subtype of PCa different from adenocarcinoma or received HIFU treatment in centres differing from the ones mentioned above.

Sonablate $^{\circledR}$, Ablatherm ${ }^{\circledR}$ or Focal One ${ }^{\circledR}$ software were used for S-HIFU treatment planning. All patients received whole-gland treatment. Additional transurethral resection of the prostate was not routinely performed. Postoperatively, patients received levofloxacin for 10 days, tamsulosin for 3 months and oral analgesics if needed. No adjuvant ADT was administered. Patients were usually discharged from hospital the day after the procedure with a suprapubic catheter for 2-4 weeks with catheter removal depending on individual voiding function.

S-RP treatments were performed by an open retropubic approach with the exception of two patients who underwent a salvage robot-assisted radical prostatectomy (S-RARP). S-RP treatments were non nerve-sparing with extended pelvic lymphadenectomy (external iliac, obturator fossa and internal iliac nodes). Patients received cefazolin at induction. Postoperatively, low-molecular-weight heparin was administered subcutaneously for 1 month and oral analgesics and anticholinergics were administered if needed. Patients were usually discharged from hospital one week after the procedure with a transurethral catheter for 3 weeks. A cysto-urethrography was performed prior to catheter removal to ensure no leakage was identified. 
To note, both procedures were performed by experienced surgeons, S-HIFU by (SJ, RVV) and S-RP by (SJ, HVP). Patient post-operative follow-up consisted of clinical and biochemical evaluation at 3 months interval during the first year post-operatively and every 6 months thereafter. No systematic or additional biopsies were routinely taken. In case of BCR, diagnostic imaging was conducted using abdominopelvic CT or MRI combined with a bone scan. ${ }^{11} \mathrm{C}$-Choline or ${ }^{68} \mathrm{Ga}$-PSMA PET-CT scans were optional and dependent on availability. BCR was based on the Phoenix definition after SHIFU and as two consecutive PSA values $>0.2 \mathrm{ng} / \mathrm{mL}$ and rising after S-RP [8-10].

The primary endpoints included estimated OS, CSS and MFS at 5 years using the Kaplan-Meier method with Log-rank test. Secondary endpoints included incontinence and perioperative complications. Continence was measured at 6 and 12 months after LST and was scored according to the number of pads used per day: no incontinence or terminal dribbling, mild incontinence (1 pad), moderate incontinence (2 pads) or severe incontinence ( 3 or more pads, or need for incontinence surgery or urinary diversion). Peri- and postoperative complications were graded according to the Clavien-Dindo classification of surgical complications. Incontinence and Clavien-Dindo complications were retrospectively extracted from detailed chart reviews. Analyses were done using the statistical software package Medcalc $^{\circledR}$. A p-value $<0.05$ was considered statistically significant.

\section{Results}

27 S-HIFU and 25 S-RP patients met the inclusion criteria (Figure 1). All S-HIFU patients had received prostate-only RT. Two S-RP patients had received whole-pelvic RT, while the remainder had received prostate-only $\mathrm{RT}$ or BT.

Patient characteristics are listed in Table 1. At the time of primary treatment, the S-HIFU and S-RP groups were similar with respect to D'Amico classification, and mean received RT doses. However, at the time of LST, S-RP patients were significantly younger and healthier. In addition, even though nonsignificantly different from the S-HIFU group, the S-RP group included a higher number of patients with short PSA-DT, higher PSA and Gleason score $\geq 4+4$. Furthermore, the S-HIFU group did not contain BT patients ( 0 vs. $8, \mathrm{p}=0.0016$ ). ADT use within 90 days prior to LST was noted in $31 \%$ of patients $(7 / 27(26 \%)$ in the S-HIFU group vs. $9 / 25(36 \%)$ in the S-RP group $(\mathrm{p}=0.4361))$.

Surgery and pathology details are presented in Table 2. S-HIFU treatment was associated with a shorter operating time $(\mathrm{p}=0.0261)$ and a shorter hospital stay $(\mathrm{p}<0.0001)$ compared to S-RP. Median (range) follow-up was 45.0 (2-168) months for S-HIFU vs. 43.0 (1-229) months for S-RP $(\mathrm{p}=0.9198)$. The mean (SD) PSA nadir was 1.4 (2.1) (median 0.13, range 0.00-2.64) for S-HIFU vs. $0.1(0.1)$ (median 0.03, range 0.0-0.45) for S-RP ( $\mathrm{p}=0.0112)$. 23/25 (92\%) S-RP patients underwent pelvic lymph node dissection (PLND) and 7/25 (28\%) were pN1 at final pathology.

\section{Primary endpoint}

When comparing oncological outcomes of S-HIFU vs. S-RP, no significant differences were found in estimated 5-year OS (80.9\% vs. 61.9\%, $\mathrm{p}=0.2391)$, 5-year CSS $(84.0 \%$ vs. $74.0 \%, \mathrm{p}=0.3578)$ and 5year MFS (60.3\% vs. $55.2 \%, \mathrm{p}=0.5481)$ (Figure 2). Of all patients included, $36.5 \%$ were free from hormonal therapy at last follow-up $(9 / 27 \mathrm{~S}-\mathrm{HIFU}$ vs. 10/25 S-RP patients, $\mathrm{p}=0.6213)$.

\section{Secondary endpoints}

No significant differences in continence status were found at 6 months. However, we observed a significant difference in pad-dependent status at 12 months $(22.2 \%$ vs. $56.0 \%, p=0.0104)$ (Figure $3)$. 
We observed a significant difference in the total number of Clavien $\geq$ III complications $(9 / 27$ patients vs. $16 / 25$ patients, $\mathrm{p}=0.027$ ) (Table 3). However, when assessed on an individual level, no significant difference was found in the number of patients who experienced a Clavien $\geq I I I$ complication (7/27 vs. $12 / 25, p=0.1019)$. Complications of all grades (Clavien I-V) were common in both groups with the exception of urinary retention $(11 / 27$ in the S-HIFU vs. $0 / 25$ in the S-RP groups, $p=0.0003$ ] and rectal fistula $(1 / 27$ in the S-HIFU vs. $4 / 25$ in the S-RP groups, $p=0.1829)$. Indeed, one S-HIFU and four S-RP patients developed a recto-urinary fistula. The S-HIFU patient had high-risk PCa before RT, and still had cT2, Gleason score $4+5$ disease before S-HIFU. He was managed with a temporary colostomy followed by cystoprostatectomy with urinary diversion. Of the 4 patients who developed a recto-urinary fistula following S-RP, 2 had low-risk, 1 had intermediate-risk and 1 had high-risk disease before RT. Before S-RP, 3 of them had Gleason $\geq 4+4$ (one 3+4), 2 had cT1, 1 cT2 and 1 cT3 disease. One fistula spontaneously resolved after temporary ileostomy, one was repaired with gracilis muscle interposition, another was managed with fistulectomy and augmentation cystoplasty, and the fourth with cystectomy and neobladder.

\section{Discussion}

We report oncological, functional and toxicity outcomes in a retrospective comparison between SHIFU and S-RP for radiation-recurrent nonmetastatic PCa. We found comparable mid-term oncological outcomes for both groups. Early continence was comparable, however at longer-term follow-up, S-RP was associated with a higher risk of being pad-dependent. Total number of complications was comparable between groups, but high-grade complications were more common in the S-RP group. On an individual-based analysis, however, similar numbers of patients in both groups experienced high-grade complications.

According to EAU guidelines, LST can be considered for patients with a low comorbidity index, a life-expectancy of more than 10 years, organ-confined PCa (T1-T2), Gleason score $\leq 7$ and a PSA < $10 \mathrm{ng} / \mathrm{mL}$ before LST [11]. 8/27 (29.6\%) S-HIFU and 7/25 (28.0\%) S-RP patients in our analysis met these criteria while $37 / 52(71.2 \%)$ patients did not. Therefore, our cohort potentially represents higherrisk disease compared to other salvage series. However, the oncological outcomes in our study remained comparable to other published series from the last decade $[1,11]$.

Concerning functional outcomes, we observed a significant difference in pad-dependent status 12 months after LST (22.2\% for S-HIFU vs. $56.0 \%$ for S-RP, $\mathrm{p}=0.0104)$. This is consistent with a meta-regression analysis from 2015 which included 63 studies to compare oncological, functional and toxicity outcomes of S-RP versus three nonsurgical modalities, including S-HIFU. In that analysis, S-RP appeared to have the highest risk of urinary incontinence [12]. Kenney et al. hypothesized that loss of the bladder neck during S-RP unmasks a preexisting damage to the external sphincter due to RT, resulting in incontinence [13].

We observed a significant difference in the total number of Clavien $\geq$ III complications between groups. Recorded individual complications (Clavien I-V) were common in both groups, except a higher risk of urinary retention in the S-HIFU group and a higher risk of recto-urinary fistulas in the S-RP group. Urinary retention in the S-HIFU group was caused by sloughing of necrotic tissue in the prostatic urethra, requiring endoscopic intervention. Rectal injury encountered during S-RP was probably related to extensive fibrosis after RT with subsequently more difficult visualization of the dissection plane between rectum and prostate. Two senior surgeons performed the S-HIFU (SJ, RVV) and two performed the S-RP procedures (SJ, HVP). More than 300 HIFU procedures and more than 4000 open and robot-assisted radical prostatectomies were performed in the primary setting over the study period in both centers jointly. This provides evidence of expertise for involved surgeons and reflects the high load of participating centers. 
Our high total number of Clavien $\geq$ II complications of 21/25 (84.0\%) for S-RP compared to a systematic review of S-RARP case series, where an overall complication rate CD $\geq$ II of 31/190 (16.3\%) was reported, suggests that robotic surgery as LST results in some advantage with regard to the rates of serious complications [10,14]. However, only limited retrospective series compared open S-RP to S-RARP. S-RARP could improve toxicity outcomes by ameliorating surgical definition and tissue handling compared to S-RP. When assessing rectal injury rates in particular from 2 different reviews, 16/339 (4.72\%) S-RP vs. 2/197 (1.0\%) S-RARP patients had rectal injury [1, 14]. Even though direct comparison between both studies should not be done, these data suggest slightly better toxicity outcomes for S-RARP.

Functional results might be better with S-RARP, but this remains to be clarified. Chade et al. reported in a systematic review continence rates, defined by zero pads after open S-RP, ranging from $21 \%$ to $90 \%$, while in robotic studies, it ranged from $33 \%$ to $80 \%$ (except a small study with six cases and no incontinent patients) [11]. Zargar et al. reported in 10 S-RARP case series an overall continence rate of $60.4 \%$ (119/197) at mean 18.6 months follow-up, although definitions of continence were variable [14]. When assessing functional outcomes, characteristics other than type of surgery such as surgical experience, the variability of nerve sparing techniques, continence and erectile function before LST need to be considered. Since open RP is still often performed throughout the world and only very limited data favor S-RARP over S-RP, we believe our study is relevant to contemporary practice.

ADT has been used frequently in patients experiencing BCR following EBRT or BT. The objective of ADT should be to improve OS, postpone metastatic progression, and improve quality of life. Biochemical response only holds no clinical benefit for a patient. For older patients and those with comorbidities, the side-effects of ADT may even decrease life expectancy [15]. The EAUESTRO-SIOG guidelines on PCa recommend that in patients with BCR following EBRT or BT not suitable for curative treatment, ADT should be used only for symptom palliation [16]. Sadly enough, although ADT offers no chance of cure, in a recent CaPSURE database analysis salvage therapy in patients with BCR following EBRT or BT consisted of ADT in $93.5 \%$ of 587 men, with only $2 \%$ of patients receiving LST [17]. For the above mentioned reasons, we believe that LST may offer patients a treatment with curative intent. A watchful waiting approach or ADT should only be offered to patients unwilling to undergo LST or having a life expectancy deemed too short to benefit from LST.

This study has only dealt with whole-gland S-HIFU. Although PCa is a multifocal disease, emergence of focal therapies ablating the index lesion with surveillance of the clinically insignificant lesions seem attractive due to potentially avoiding the morbidity of salvage surgery or whole-gland ablation [5, 18-19]. Kanthabalan et al. recently analyzed 150 men who underwent focal S-HIFU with reasonable short-term oncological, functional and toxicity outcomes [20]. Improvements in HIFU technology and imaging-directed HIFU treatment (hemiablation, focal treatment) could further result in decreased functional morbidity while preserving adequate oncological outcomes [21].

S-HIFU is a targeted local therapy not intervening with undetected metastases. In S-RP, pelvic lymph nodes are often simultaneously dissected. Since PLND in S-RP is not standardized, the impact on survival and comparison between studies is hard to analyze. Based on data from the the Surveillance, Epidemiology, and End Results (SEER) 18 registry, Pokala N et al. studied the effect of PLND status and number of nodes retrieved in patients undergoing S-RP. The hazard of mortality was higher in men who did not undergo PLND with a hazard ratio of 1.4 for OS $(p=0.2)$ and 2.7 for CSS $(\mathrm{p}=0.01)$ [22]. No significant increase in OS or CSS was seen with increasing number of lymph nodes retrieved. When carefully assessing the pre-salvage PSA, PSA-DT and Gleason scores (all recognized predictors of poor outcome) in our series, patients who underwent S-RP had (nonsignificantly) worse parameters compared to those who underwent S-HIFU. Moreover, in our series, 23/25 (92\%) of patients underwent PLND, and 7/25 (28\%) of patients were pN1 at final histopathology. The reason why S-HIFU resulted in comparable outcomes compared to S-RP in a group of patients in which poor prognostic factors were 
more prevalent in the S-RP group, might be explained by the positive effect of the PLND. Even though this effect remains to be proven, we advocate to perform a PLND at the time of S-RP.

This study has several limitations. It is retrospective in nature with a limited number of patients which might have hindered the detection of differences between groups. In addition, no propensity score matching was used for the two groups to reduce bias due to potential confounding variables. Regarding incontinence, no patient reported outcome measures were available. Erectile function was not assessed due to limited baseline and postoperative information from the chart reviews and a lack of standardized questionnaires.

\section{Conclusion}

Our data support the view that both S-HIFU and S-RP could be considered as valuable LST options for patients with local radiation-recurrent nonmetastatic PCa with sufficient life expectancy and a low comorbidity index. S-RP is associated with more pad-dependent patients 12 months after LST. High-grade complications were more common in the S-RP group. On an individual-based analysis, however, similar numbers of patients in both groups experienced high-grade complications. Prospective multicenter group-matched trials with long-term follow-up are needed to establish clinically applicable significance. Although S-HIFU is a less invasive technique than S-RP, it is of critical importance to be aware of major complications such as bladder neck stricture or rectourinary fistula in the salvage setting.

\section{Compliance with Ethical Standards}

Disclosure of potential conflicts of interest: W. Everaerts is a company consultant for Astellas, Medtronic, Bayer and Janssen; has received company speaker honoraria from Astellas and Janssen. S. Joniau is a company consultant for Astellas, Ipsen, Bayer, Sanofi, and Janssen; has received company speaker honoraria from Astellas, Amgen, Bayer, Sanofi, Janssen, and Ipsen; has participated in trials for Astellas, Janssen, and Bayer; has received fellowship and travel grants from Astellas, Amgen, Bayer, Sanofi, Janssen, Ipsen, and Pfizer; and has received grant and research support from Astellas, Bayer, and Janssen. The other authors declare that they have no conflict of interest.

Research involving Human Participants and/or Animals: This article does not contain any studies with human participants or animals performed by any of the authors.

Informed consent: This is a retrospective study. For this type of study formal consent is not required. 


\section{Figure legend}

Fig. 1 Consort diagram showing selection of patients for analysis.

Fig. 2 Kaplan-Meier curves predicting (a) OS, (b) CSS, (c) MFS and (d) bDFS following LST. Note that bDFS was defined as PSA nadir $+2 \mathrm{ng} / \mathrm{mL}$ after S-HIFU and as two consecutive PSA values $>0.2$ $\mathrm{ng} / \mathrm{mL}$ and rising after S-RP.

Fig. 3 (a) Incontinence rates 12 months after LST in terms of pads used per day; (b) Comparison of pad free vs. pad-dependent patients between groups. We observed a significant difference in pad-dependent status 12 months after LST (22.2\% vs. $56.0 \%, \mathrm{p}=0.0104)$; AUS = artificial urinary sphincter; NA = not available; $\bullet$ Chi-squared test.

\section{References}

1. Golbari NM, Katz AE (2017) Salvage Therapy Options for Local Prostate Cancer Recurrence After Primary Radiotherapy: a Literature Review. Curr Urol Rep; 18: 63. doi: 10.1007/s11934-017-07094

2. Kimura M, Mouraviev V, Tsivian M, Mayes JM, Satoh T, Polascik TJ (2010) Current salvage methods for recurrent prostate cancer after failure of primary radiotherapy. BJU Int; 105: 191-201. doi: 10.1111/j.1464-410X.2009.08715.x

3. Ehdaie B, Atoria CL, Gupta A, Feifer A, Lowrance WT, Morris MJ et al (2012) Androgen deprivation and thromboembolic events in men with prostate cancer. Cancer; 118: 3397-406. doi: $10.1002 /$ cncr.26623

4. Bolla M, Van Tienhoven G, Warde P, Dubois JB, Mirimanoff RO, Storme G et al (2010) External irradiation with or without long-term androgen suppression for prostate cancer with high metastatic risk: 10-year results of an EORTC randomised study. Lancet Oncol; 11: 1066-1073. doi: 10.1016/S1470-2045(10)70223-0

5. Crouzet S, Blana A, Murat FJ, Pasticier G, Brown SCW, Conti GN et al (2017) Salvage highintensity focused ultrasound (HIFU) for locally recurrent prostate cancer after failed radiation therapy: Multi-institutional analysis of 418 patients. BJU Int; 119: 896-904. doi: 10.1111/bju. 13766

6. Scheltema MJ, van den Bos W, Siriwardana AR, Kalsbeek AMF, Thompson JE, Ting F et al (2017) Feasibility and safety of focal irreversible electroporation as salvage treatment for localized radiation-recurrent prostate cancer. BJU Int; 120: 51-58. doi: 10.1111/bju.13991

7. Parekh A, Graham PL, Nguyen PL (2013) Cancer control and complications of salvage local therapy after failure of radiotherapy for prostate cancer: a systematic review. Semin Radiat Oncol; 23: 222-34. doi: 10.1016/j.semradonc.2013.01.006

8. Amling, C.L., Bergstralh EJ, Blute ML, Slezak JM, Zincke H (2001) Defining prostate specific antigen progression after radical prostatectomy: what is the most appropriate cut point? J Urol; 165 : 1146. 
9. Roach M 3rd, Hanks G, Thames H Jr, Schellhammer P, Shipley WU, Sokol GH et al (2006) Defining biochemical failure following radiotherapy with or without hormonal therapy in men with clinically localized prostate cancer: recommendations of the RTOG-ASTRO Phoenix Consensus Conference. Int J Radiat Oncol Biol Phys; 65: 965. doi: 10.1016/j.ijrobp.2006.04.029

10. Matei DV, Ferro M, Jereczek-Fossa BA, Renne G, Crisan N, Bottero D et al (2015) Salvage radical prostatectomy after external beam radiation therapy: a systematic review of current approaches. Urol Int; 94: 373-82. doi: 10.1159/000371893

11. Chade DC, Eastham J, Graefen M, Hu JC, Karnes RJ, Klotz L et al (2012) Cancer control and functional outcomes of salvage radical prostatectomy for radiation-recurrent prostate cancer: a systematic review of the literature. Eur Urol; 61: 961. doi: 10.1016/j.eururo.2012.01.022

12. Philippou Y, Parker RA, Volanis D, Gnanapragasam VJ (2016) Comparative Oncologic and Toxicity Outcomes of Salvage Radical Prostatectomy Versus Nonsurgical Therapies for Radiorecurrent Prostate Cancer: A Meta-Regression Analysis. Eur Urol Focus; 2: 158-171. doi: 10.1016/j.euf.2015.09.004

13. Kenney PA, Nawaf CB, Mustafa M, Wen S, Wszolek MF, Pettaway CA et al (2016) Roboticassisted laparoscopic versus open salvage radical prostatectomy following radiotherapy. Can J Urol; 23: 8271-7.

14. Zargar H, Lamb AD, Rocco B, Porpiglia F, Liatsikos E, Davis J et al (2017) Salvage robotic prostatectomy for radio recurrent prostate cancer: technical challenges and outcom e analysis. Minerva Urol Nefrol; 69: 26-37. doi: 10.23736/S0393-2249.16.02797-1

15. Levine GN, D'Amico AV, Berger P, Clark PE, Eckel RH, Keating NL et al (2010) Androgendeprivation therapy in prostate cancer and cardiovascular risk: a science advisory from the American Heart Association, American Cancer Society, and American Urological Association: endorsed by the American Society for Radiation Oncology. Circulation; 121: 833-40. doi: 10.1161/CIRCULATIONAHA.109.192695

16. Cornford P, Bellmunt J, Bolla M, Briers E, De Santis M, Gross T et al (2017) EAU-ESTRO-SIOG Guidelines on Prostate Cancer. Part II: Treatment of Relapsing, Metastatic, and Castration-Resistant Prostate Cancer. Eur Urol; 71: 630-642. doi: 10.1016/j.eururo.2016.08.002

17. Tran H, Kwok J, Pickles T, Tyldesley S, Black PC (2014) Underutilization of local salvage therapy after radiation therapy for prostate cancer. Urol Oncol; 32: 701-6. doi: 10.1016/j.urolonc.2013.12.014

18. Duijzentkunst DA, Peters M, van der Voort van Zyp JR, Moerland MA, van Vulpen M (2016) Focal salvage therapy for local prostate cancer recurrences after primary radiotherapy: a comprehensive review. World J Urol; 34: 1521-1531. doi: 10.1007/s00345-016-1811-9

19. Bott SR, Ahmed HU, Hindley RG, Abdul-Rahman A, Freeman A, Emberton M (2010) The index lesion and focal therapy: an analysis of the pathological characteristics of prostate cancer. BJU Int; 106:1607-11. doi: 10.1111/j.1464-410X.2010.09436.x

20. Kanthabalan A, Peters M, Van Vulpen M, McCartan N, Hindley RG, Emara A (2017) Focal salvage high-intensity focused ultrasound in radiorecurrent prostate cancer. BJU Int; 120:246-256. doi: 10.1111/bju.13831 
21. Golan R, Bernstein AN, McClure TD, Sedrakyan A, Patel NA, Parekh DJ et al (2017) Partial Gland Treatment of Prostate Cancer Using High-Intensity Focused Ultrasound in the Primary and Salvage Settings: A Systematic Review. J Urol. 198:1000-1009. doi: 10.1016/j.juro.2017.03.137

22. Pokala N, Huynh DL, Henderson AA, Johans C (2016) Survival Outcomes in Men Undergoing Radical Prostatectomy After Primary Radiation Treatment for Adenocarcinoma of the Prostate. Clin Genitourin Cancer; 14: 218-25. doi: 10.1016/j.clgc.2015.12.010 


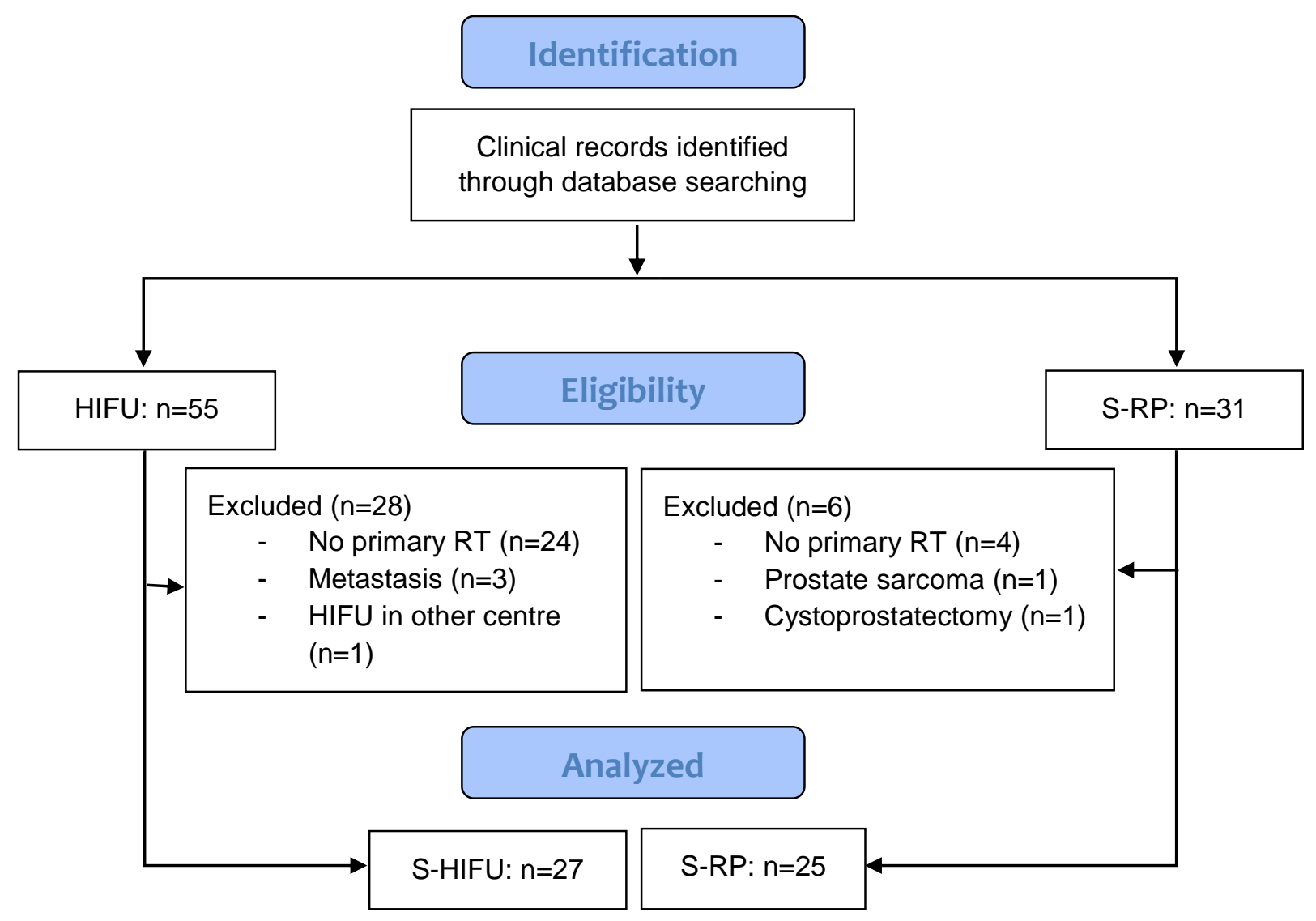

Fig. 1 
a

Overall survival

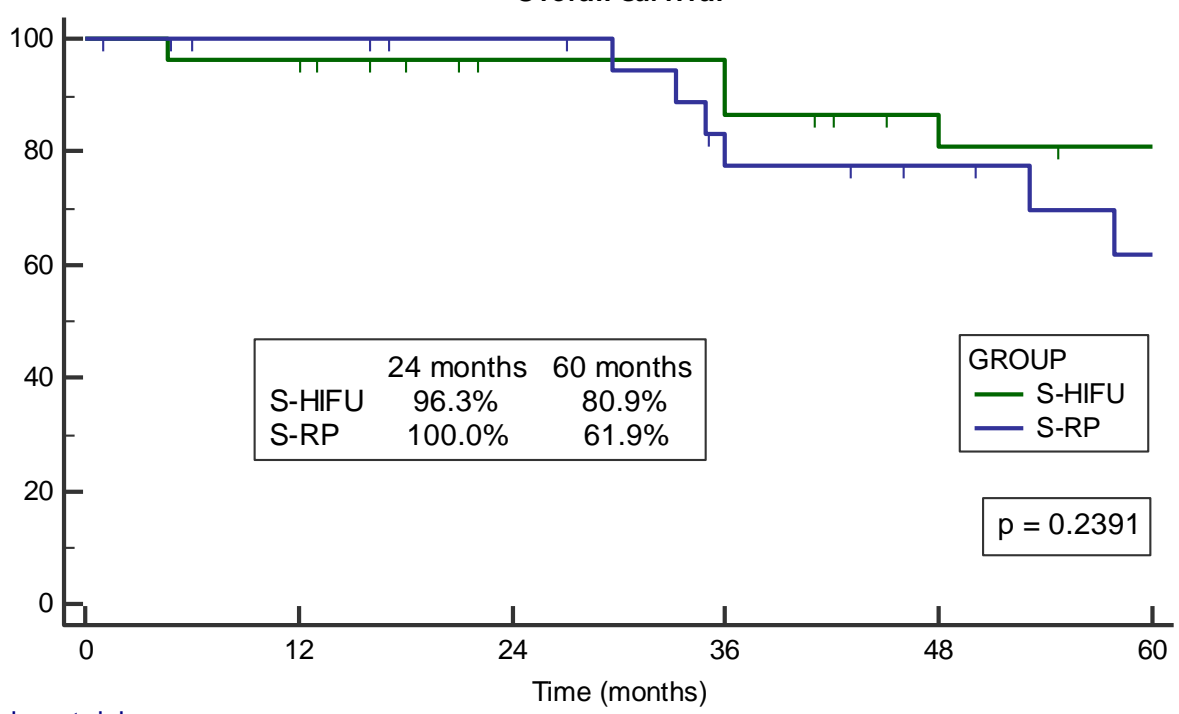

Number at risk

Group: S-HIFU

Group: S-RP

25

25

20

18

14

13

22

19

13

11

8

b

Cancer-specific survival

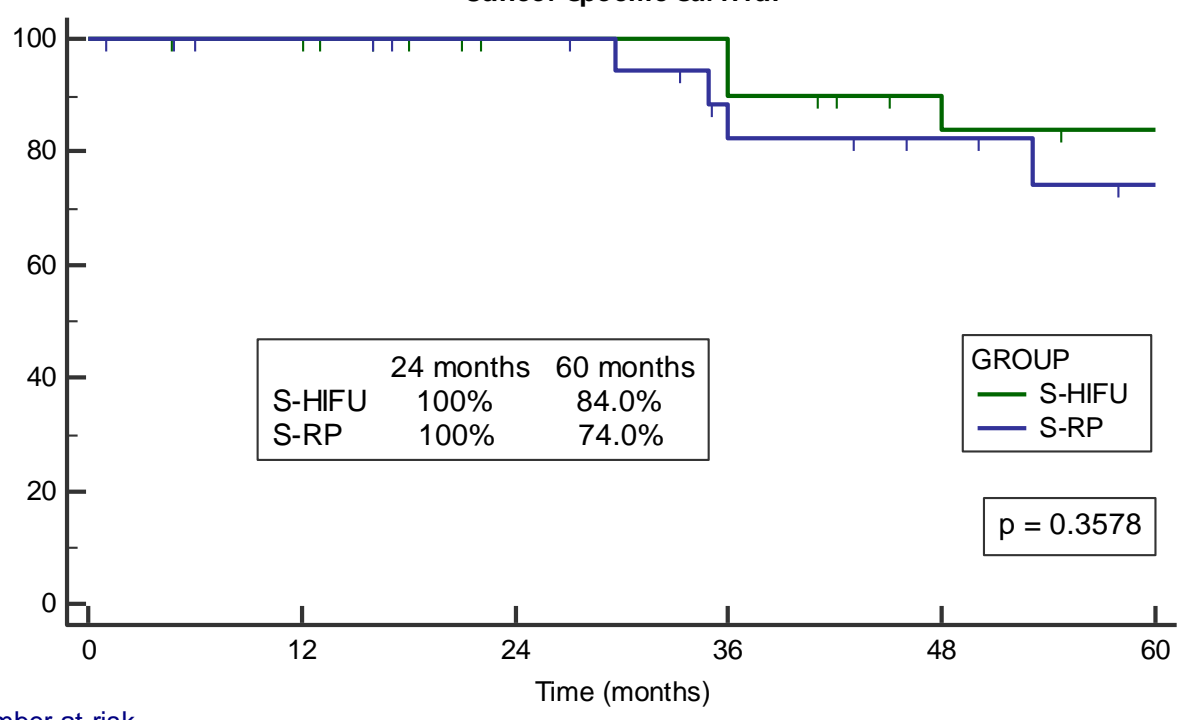

Number at risk

Group: S-HIFU

Group: S-RP

25

20

18

14

13

25

22

19

13

11

8 
c

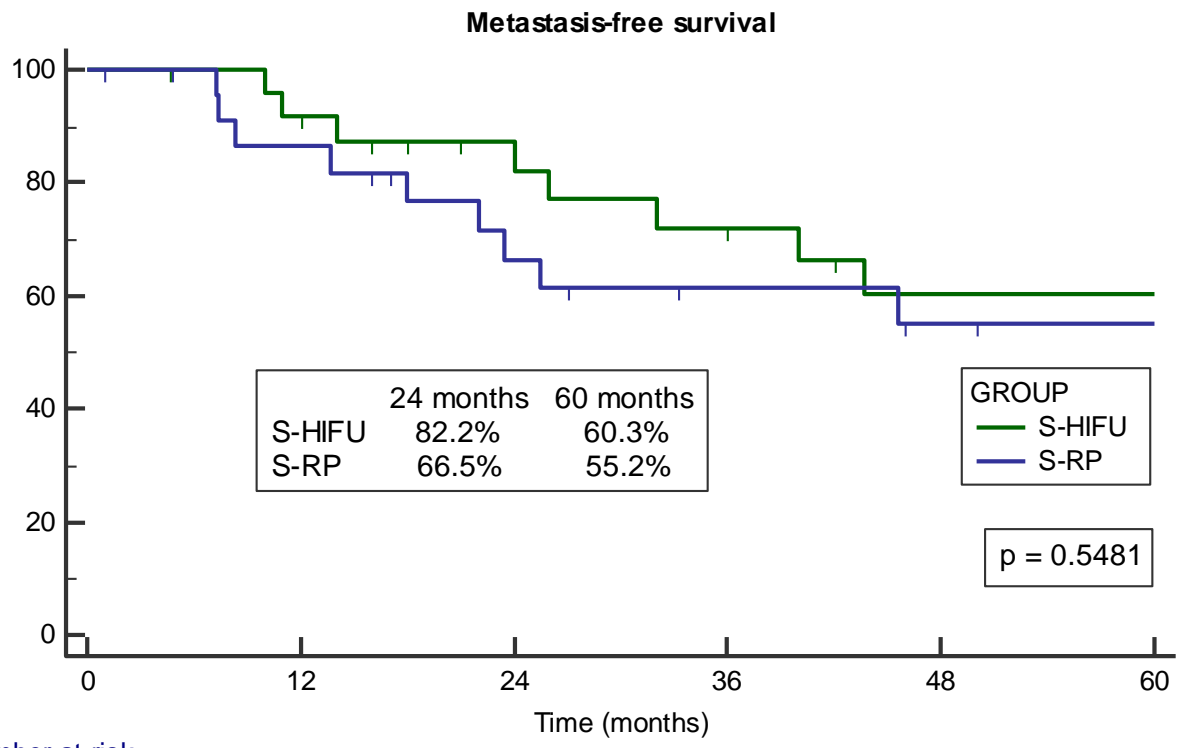

Number at risk

Group: S-HIFU

25
Group: S-RP
24

21

19

13

13

10

10

10

8

7

d

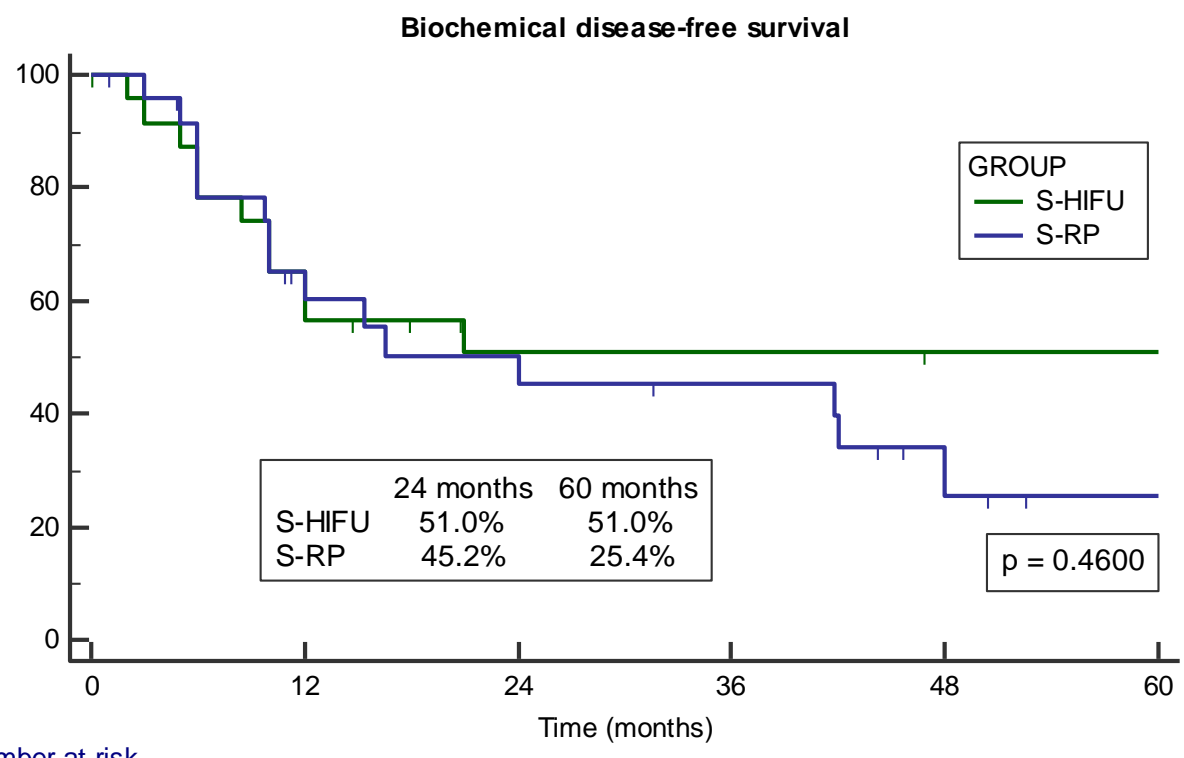

Number at risk

Group: S-HIFU

\begin{tabular}{|c|c|c|c|c|c|}
\hline 24 & 13 & 9 & 9 & 8 & 8 \\
\hline Group: S-RP & & & & & \\
\hline 25 & 12 & 9 & 8 & 3 & 1 \\
\hline
\end{tabular}

Fig. 2 
a

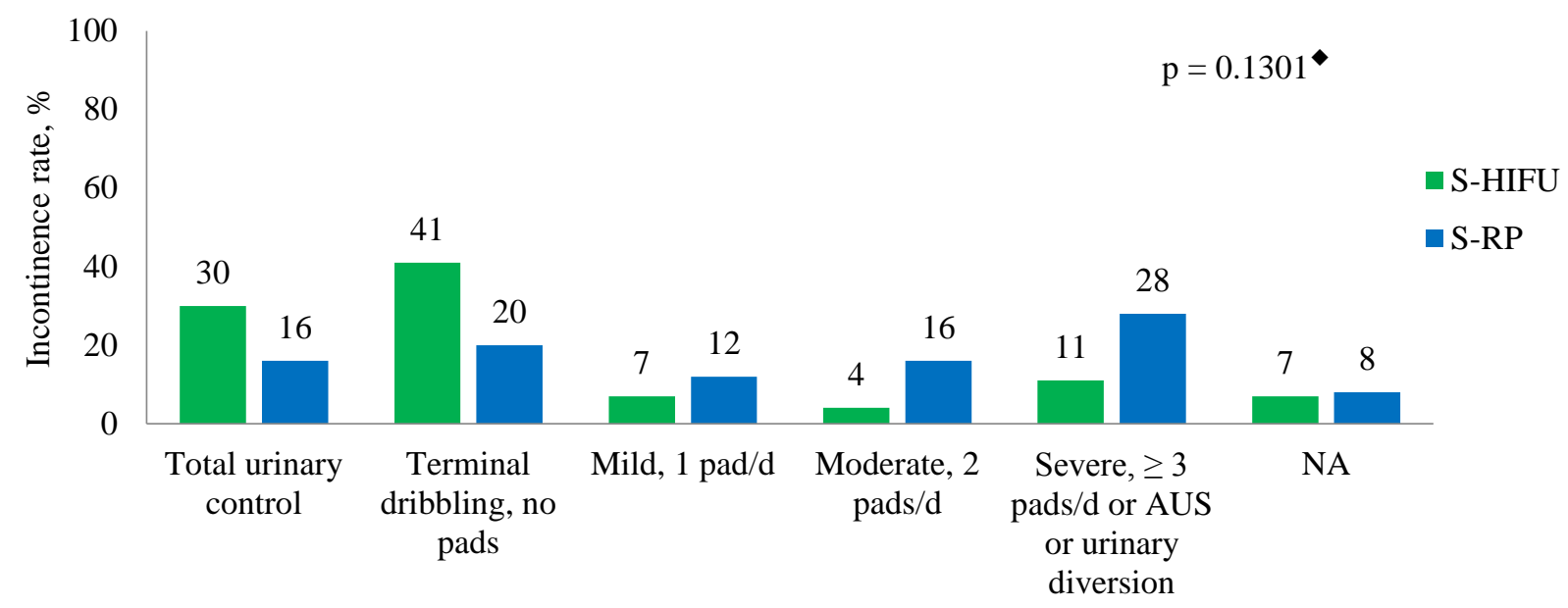

b

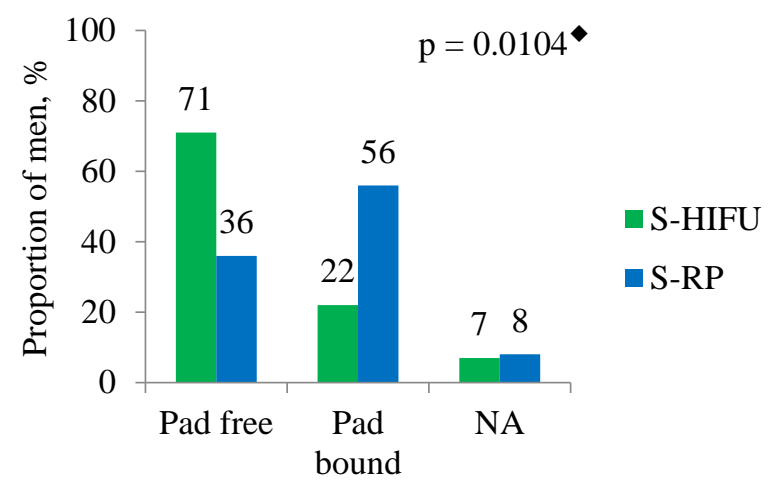

Fig. 3 
Table 1

\begin{tabular}{|c|c|c|c|}
\hline Feature & S-HIFU & S-RP & p-value \\
\hline Number of patients & 27 & 25 & \\
\hline $\begin{array}{ll}\text { Age, } & \text { years } \\
- & \text { Mean (SD) } \\
- & \text { Median (range) }\end{array}$ & $\begin{array}{l}69.9(6.2) \\
69.2(54.0-80.0)\end{array}$ & $\begin{array}{l}63.7(6.6) \\
65.0(52.0-75.6)\end{array}$ & $0.0045^{\diamond}$ \\
\hline $\begin{array}{c}\text { ASA, no. }(\%) \\
-\quad \text { ASA } 1 \\
-\quad \text { ASA 2 } \\
-\quad \text { ASA 3 }\end{array}$ & $\begin{array}{l}4(14.8) \\
16(59.3) \\
7(25.9)\end{array}$ & $\begin{array}{l}13(52.0) \\
10(40.0) \\
2(8.0)\end{array}$ & $0.0119^{\diamond}$ \\
\hline $\begin{aligned} \text { Pre-RT } & \text { risk (D'Amico classification), no. (\%) } \\
- & \text { Low } \\
- & \text { Intermediate } \\
- & \text { High } \\
- & \text { NA }\end{aligned}$ & $\begin{array}{l}4(14.8) \\
7(25.9) \\
16(59.3) \\
0\end{array}$ & $\begin{array}{l}9(36.0) \\
5(20.0) \\
8(32.0) \\
3\end{array}$ & $0.1076^{\star}$ \\
\hline $\begin{array}{cl}\text { PSA before LST, } \mathbf{n g} / \mathrm{mL} \\
-\quad \text { Mean (SD) } \\
-\quad \text { Median (range) }\end{array}$ & $\begin{array}{l}4.3(3.6) \\
3.2(0.2-11.4)\end{array}$ & $\begin{array}{l}5.3(2.9) \\
4.6(1.4-11.9)\end{array}$ & $0.0672^{\diamond}$ \\
\hline $\begin{array}{cl}\text { PSA-DT before LST, no. }(\%) \\
-\quad<12 \text { months } \\
-\quad \geq 12 \text { months } \\
-\quad \text { NA }\end{array}$ & $\begin{array}{l}13(48.1) \\
10(37.0) \\
4\end{array}$ & $\begin{array}{l}16(64.0) \\
5(20.0) \\
4\end{array}$ & $0.1741^{\star}$ \\
\hline $\begin{aligned} \text { RT modality, no. }(\%) \\
-\quad \text { EBRT } \\
-\quad \text { Brachytherapy }\end{aligned}$ & $\begin{array}{l}27(100) \\
0(0)\end{array}$ & $\begin{array}{l}17(68.0) \\
8(32.0)\end{array}$ & $0.0016^{\bullet}$ \\
\hline $\begin{array}{cl}\text { RT } & \text { dose, Gy } \\
- & \text { Mean (SD) } \\
- & \text { Median (range) }\end{array}$ & $\begin{array}{l}70.7(2.7) \\
70.0(66.0-78.0)\end{array}$ & $\begin{array}{l}70.1(3.3) \\
70.0(64.0-78.0)\end{array}$ & $0.6032^{\diamond}$ \\
\hline $\begin{aligned} \text { Gleason score before LST, no. }(\%) \\
-\quad \leq 3+3 \\
-\quad 3+4 \\
-\quad 4+3 \\
-\quad \geq 4+4 \\
-\quad \text { NA }\end{aligned}$ & $\begin{array}{l}3(11.1) \\
4(14.8) \\
6(22.2) \\
10(37.0) \\
4\end{array}$ & $\begin{array}{l}2(8.0) \\
3(12.0) \\
3(12.0) \\
12(48.0) \\
5\end{array}$ & $0.7240^{\bullet}$ \\
\hline Median (range) Charlson comorbidity index & $5(3-7)$ & $4(3-5)$ & \\
\hline
\end{tabular}

S-HIFU = salvage high intensity focused ultrasound; S-RP = salvage radical prostatectomy; SD = standard deviation; $\mathrm{NA}=$ not available; $\mathrm{PSA}=$ prostate specific antigen; $\mathrm{LST}=$ local salvage therapy; PSA-DT $=$ PSA doubling time; $\mathrm{RT}=$ radiotherapy; EBRT $=$ external beam radiation therapy; ASA = American Society of Anesthesiologists classification; ${ }^{\diamond}$ Mann-Whitney test. ${ }^{\star}$ Chi-squared test. 
Table 2

\begin{tabular}{|c|c|c|c|}
\hline & S-HIFU (n=27) & S-RP $(n=25)$ & p-value \\
\hline Mean (SD) surgery duration (minutes) & $132.4(28.6)$ & $166.0(53.5)$ & $0.0261^{\diamond}$ \\
\hline Mean (SD) estimated blood loss (mL) & - & $808.0(593.6)$ & \\
\hline Mean (SD) length of stay (days) & $3.9(4.7)$ & $12.3(6.3)$ & $<0.0001^{\diamond}$ \\
\hline $\begin{array}{cc}\text { Pathologic stage, no. }(\%) \\
-\quad \text { pT0 } \\
-\quad \text { pT1 } \\
-\quad \text { pT2 } \\
-\quad \text { pT3 } \\
-\quad \text { pT4 } \\
-\quad \text { NA }\end{array}$ & - & $\begin{array}{l}2(8.0) \\
0 \\
7(28.0) \\
14(56.0) \\
0 \\
2(8.0)\end{array}$ & \\
\hline $\begin{aligned} \text { Pathologic Gleason score, no. }(\%) \\
-\quad \leq 3+3 \\
-\quad 3+4 \\
-\quad 4+3 \\
-\quad \geq 4+4 \\
-\quad \text { NA }\end{aligned}$ & - & $\begin{array}{l}2(8.0) \\
5(20.0) \\
3(12.0) \\
12(48.0) \\
3(12.0)\end{array}$ & \\
\hline Positive surgical margin, no. (\%) & - & $11(44.0)$ & \\
\hline Positive nodes, no. (\%) & - & $7(28.0)$ & \\
\hline Median (range) nodes retrieved & - & $17.0(0-40)$ & \\
\hline
\end{tabular}


Table 3

\begin{tabular}{|c|c|c|c|c|c|c|c|c|c|}
\hline & \multicolumn{2}{|c|}{ No. $\leq 30$ days } & \multicolumn{2}{|c|}{ No. 31-90 days } & \multicolumn{2}{|c|}{ No. $>90$ days } & \multicolumn{2}{|c|}{ Overall, no. (\%) } & \multirow[t]{2}{*}{ p-value } \\
\hline & S-HIFU & S-RP & S-HIFU & S-RP & S-HIFU & S-RP & S-HIFU & S-RP & \\
\hline Clavien I & 2 & 1 & 0 & 0 & 0 & 0 & $2(6.3)$ & $1(4.0)$ & $0.6021 *$ \\
\hline $\begin{array}{cl}\text { Clavien II } \\
- & \text { Clot retention } \\
- & \text { Urinary tract infection } \\
- & \text { Urinary retention }\end{array}$ & $\begin{array}{l}2 \\
2 \\
2\end{array}$ & $\begin{array}{l}0 \\
3 \\
0\end{array}$ & $\begin{array}{l}0 \\
5 \\
2\end{array}$ & $\begin{array}{l}0 \\
1 \\
0\end{array}$ & $\begin{array}{l}0 \\
1 \\
7\end{array}$ & $\begin{array}{l}0 \\
1 \\
0\end{array}$ & $\begin{array}{c}\mathbf{2 1} \\
2(6.3) \\
8(25.0) \\
11(34.4)\end{array}$ & $\begin{array}{c}\mathbf{5} \\
0 \\
5(20.0) \\
0\end{array}$ & $\begin{array}{l}<0.0001 * \\
0.4910^{*} \\
0.5283^{*} \\
0.0003 *\end{array}$ \\
\hline $\begin{array}{cl}\text { Clavien III } \\
- & \text { Wound debridement } \\
- & \text { Rectal injury } \\
- & \text { Rectal fistula } \\
- & \text { BNS } \\
- & \text { Ureteric injury }\end{array}$ & $\begin{array}{l}0 \\
0 \\
0 \\
0 \\
0\end{array}$ & $\begin{array}{l}2 \\
4 \\
1 \\
1 \\
1\end{array}$ & $\begin{array}{l}0 \\
0 \\
0 \\
0 \\
0\end{array}$ & $\begin{array}{l}0 \\
0 \\
2 \\
2 \\
0\end{array}$ & $\begin{array}{l}0 \\
0 \\
1 \\
6 \\
2\end{array}$ & $\begin{array}{l}0 \\
0 \\
1 \\
5 \\
0\end{array}$ & $\begin{array}{c}9 \\
0 \\
0 \\
1(3.1) \\
6(18.8) \\
2(6.3)\end{array}$ & $\begin{array}{c}16 \\
2(8.0) \\
4(16.0) \\
4(16.0) \\
8(32.0) \\
1(4.0)\end{array}$ & $\begin{array}{l}0.0270^{\star} \\
0.2262^{*} \\
0.0467 * \\
0.1829 * \\
0.5364 * \\
1.0000^{*}\end{array}$ \\
\hline Clavien IV-V & 0 & 0 & 0 & 0 & 0 & 0 & 0 & $\mathbf{0}$ & \\
\hline Total no. of complications & & & & & & & $32(100)$ & $22(100)$ & \\
\hline
\end{tabular}

BNS = bladder neck stricture; ${ }^{\bullet}$ Chi-squared test; $*$ Fisher's exact test. 